Научная статья

УДК 331.101-021.352: 330.111.4

https://doi.org/10.24866/1813-3274/2021-3/34-49

\title{
ЗАРОЖДЕНИЕ РЕВОЛЮЦИОННОГО МОМЕНТА В КАТЕГОРИИ «СВОБОДНОЕ ВРЕМЯ»
}

\author{
В. П. Третьяк ${ }^{1}$, Российский университет транспорта, г. Москва, Россия \\ E-mail: v_tretyak@inbox.ru
}

\begin{abstract}
М. А. Лякина ${ }^{2}$, Петербургский государственный университет путей сообщения Императора Александра I, г. Санкт-Петербург, Россия

E-mail: malyakina@mail.ru
\end{abstract}

Аннотащчия. В постиндустриальном обществе наблюдается переход от принуждения к занятости и учёта рабочего времени граждан к креативной деятельности, основанной на использовании свободного времени. Форсайт постиндустриальной экономики направлен на поиск слабых сигналов, приближающих изживание элементов товарного производства и ведущих к формам использования свободного труда. В статье формулируется гипотеза о том, что в постиндустриальную эпоху, когда намечается доминирование шестого технологического уклада, в практике функционирования перезрелой товарной организации производства появляются формы, содержащие зарождающийся революционный момент в категории «свободное время». Историчность понимания свободного времени связывается авторами с развитием товарной организации производства. Сегодня в перезрелой форме товарноденежного производства содержатся зародыши креативной деятельности свободных индивидов грядущей общественной организации в виде исторически определённого свободного времени. Среди зарождающихся форм выделяются волонтёрская деятельность; функционирование социальных сетей; формирование безусловного основного дохода; проведение конкурсов и выделение грантов; вручение ежегодных премий за интеллектуальные результаты; стимулирование движения рационализаторов и изобретателей, которые повседневно побуждают к креативной деятельности человека, оцениваемой свободным временем.

\footnotetext{
${ }^{1}$ Владимир Петрович Третьяк, доктор экономических наук, профессор, профессор кафедры «Экономика и управление на транспорте», Российский университет транспорта, г. Москва, Россия.

2 Лякина Мария Анатольевна, кандидат экономических наук, доцент, доцент кафедры «Экономика транспорта», Петербургский государственный университет путей сообщения Императора Александра I, г. Санкт-Петербург, Россия.

(C) Третьяк В. П., Лякина М. А., 2021
} 
Ключевые слова: свободное время, рабочее время, Форсайт, технологические уклады, товарное производство, безусловный основной доход (БОД), волонтёрство, социальные сети, постиндустриальная экономика, бюджет времени, общественно необходимые затраты труда, нерабочее время, производительный труд.

Для циитирования: Третьяк В. П., Лякина М. А. Зарождение революционного момента в категории «свободное время» // Азиатско-Тихоокеанский регион: экономика, политика, право. 2021. № 3. С. 34-49. https://doi.org/10.24866/18133274/2021-3/34-49.

Original article

\title{
THE DAWN OF A REVOLUTIONARY MOMENT IN THE "FREE TIME" CATEGORY
}

\author{
V. P. Tretyak ${ }^{1}$, Russion Transport University, Moscow, Russia \\ E-mail:v_tretyak@inbox.ru
}

M. A. Lyakina ${ }^{2}$, Emperor Alexander I St. Petersburg State Transport University, Saint-Petersburg, Russia

E-mail: malyakina@mail.ru

Abstract. In the post-industrial society, there is a transition from enforcement to work and the working time accounting to creative activities based on the use of free time. Foresight of the postindustrial economy is aimed to find some signals that bring closer the counteracting of commodity production elements and lead to freedom of labor. The article proves the hypothesis that in the post-industrial era, when the dominance of the sixth technological order is outlined, in the practice of functioning of the overripe commodity organization of production, some forms appear that contain an emerging revolutionary moment in the category of "free time". Authors associate the historicity of the free time understanding with the commodity organization of production development. Nowadays, the overripe form of commodity-money production contains the embryos of creative activity of free individuals of the coming social organization in the form of historically determined free time. Volunteer activities stand out among the emerging forms; functioning of social networks; an unconditional basic income formation; competitions and grants;

\footnotetext{
${ }^{1}$ Vladimir P. Tretyak, Doctor of Economics, Professor, Professor of the Department of Economics and Management in Transport, Russian University of Transport, Moscow, Russia.

${ }^{2}$ Maria A. Lyakina, Candidate of Economic Sciences, Associate Professor, Associate Professor of the Department of Transport Economics, St. Petersburg State Transport University of Emperor Alexander I, St. Petersburg, Russia.
} 
intellectual results annual awards for; encouragement for innovators and inventors, for those who motivate creative activity of a person, assessed by free time, on a daily basis.

Keywords: free time, working time, Foresight, technological structures, commodity production, unconditional basic income (UBI), volunteering, social networks, postindustrial economy, time budget, socially necessary labor costs, non-working hours, productive labor.

For citing: Tretyak V. P., Lyakina M. A. The dawn of a revolutionary moment in the "free time" category // PACIFIC RIM: Economics, Politics, Law. 2021. No. 3. P. 34-49. https://doi.org/10.24866/1813-3274/2021-3/34-49.

Когда в быту используется понятие «свободное время», то говорящему кажется, что он произносит термин, который не требует пояснений. И правда, положение о том, что свободное время представляет собой часть нерабочего времени, является аксиомой [17]. Но из этого следует, что свободное время может существовать, с одной стороны, как понятие, связанное с необходимостью работать на кого-то, ведь только после этого можно воспользоваться свободным временем. А с другой стороны, как понятие, противоположное трудовой деятельности в условиях товарного производства.

Экономисты, социологи и философы, исследовавшие процессы превращения науки в непосредственную производительную силу, пытались через анализ редукции конкретного труда выйти на оценки его в единицах свободного времени. В период перестройки, когда шёл интенсивный процесс формирования рынков, интерес к этой проблеме значительно снизился. В настоящее время по мере упрочения постиндустриальной экономики вновь обратились к анализу данного вопроса, поскольку современный этап трансформации рынков сопровождается появлением множества форм, содержащих элементы оценки затрат творческого труда свободным временем, которые прорастают сквозь их товарное содержание.

Всё чаще вспоминается, что ещё в XVI в. английский мыслитель Т. Мор в трактате «Утопия» писал: «Всё время, остающееся между часами работы, сна и принятия пищи, предоставляется личному усмотрению каждого, но не для того, чтобы злоупотреблять им в излишествах или лености, а, чтобы на свободе от своего ремесла, по лучшему уразумению, удачно применить эти часы на какое-либо другое занятие» [1, с. 119-120].

Кстати, и здесь мы видим, что свободное время тоже трактуется автором, в конечном счёте, как процесс подготовки к трудовой деятельности. Поэтому социологи начинают дифференцировать общее время человека на рабочее, которое он занят в трудовой деятельности, и нерабочее время. Последнее распадается на время передвижения к месту работы и обратно, решение различных производ- 
ственных вопросов до и после работы, умывание, переодевание и т. д. (примерно 1-1,5 часа); на время, необходимое для домашнего труда и самообслуживания (примерно 3-4 часа); на время для удовлетворения физиологических потребностей (сон, принятие пищи, личная гигиена и т. д.) (примерно 8-9 часов). Итого 2022 часа. Таким образом, собственно свободное время составляет 3-4 часа в сутки. [2]. Такие оценки свободного времени на микроуровне давались в эпоху директивно планируемой экономики.

Рассматривая свободное время с неисторических позиций, различают три основных его типа [4]:

1) рекреационный (отдых и восстановление сил после работы);

2) рационально-потребительский (с материальной и духовной точки зрения);

3) деятельный (совмещение времяпрепровождения с каким-либо видом деятельности).

Когда знакомишься с подобными постановками вопроса о свободном времени, создаётся впечатление, что человек находится в вакууме, не связан с другими гражданами, а его главная задача - отдых и восстановление сил после работы и совмещение времяпрепровождения с каким-либо видом деятельности. При этом его главная задача - восстановить себя для дальнейшего постоянного участия в трудовом процессе. Рассматривая таким образом бюджет времени, мы имеем дело с неисторическим оцениванием свободного времени гражданина на микроуровне и молчаливо предполагаем его существование в вечной и неизменной товарной организации производства. В рамках данного подхода свободное время может характеризоваться как часть нерабочего времени, или время, отличное от рабочего.

«Свободное время (или досуг - англ. leisure) - это часть бюджета времени суточного, недельного, годового, которая относится к нерабочему времени, но органично связана с рабочим временем. ... Это значит, что экономия рабочего времени приводит к потенциальному увеличению бюджета свободного времени, но не гарантирует его обязательного превращения в последнее. Оно может перейти в прибавочное рабочее время, не выходя за пределы производственной деятельности. Понятие свободного времени в современном обществе включает в себя элементы умственной, социальной, физической активности, развлечения и отдых» [3]. Из вышеприведённой цитаты видно, что и здесь сохраняется подход, согласно которому свободное время является, в конечном счёте, подготовкой к трудовой деятельности посредством досуга.

Как оценивалось наличие свободного времени в нашей стране? В России во второй половине XIX в. свободное время составляло 500 часов в год, в СССР в 1980-е годы - почти 1800. То есть свободное время занимает у работающего человека почти столько же, сколько и рабочее (2000 часов в год) [2]. Очень 
репрезентативная информация по бюджету времени россиян в Российской Империи и Советском Союзе.

Кроме анализа бюджета времени работника и определения свободного времени на микроуровне имеются подходы, рассматривающие категорию «свободное время» на макроуровне. Так В. Я. Ельмеев отмечает, что «время деятельности вне материального производства является свободным временем общества» [5, с. 114], т. е. временем, которое не поглощается непосредственно производительным трудом, а остаётся свободным для удовольствий, для досуга. При этом труд врачей, учителей и других работников, оказывающих услуги работникам материального производства, не входит в рабочее время общества [5]. Здесь мы видим, что автор оценивает деятельность врачей, учителей, творческих работников как затраты свободного времени общества.

Указанные характеристики фиксируют, что гражданин может жить только в условиях товарно-денежных отношений. Именно поэтому наличие понятий рабочего и нерабочего времени предполагает, что гражданин должен обязательно трудиться по найму. Но так было не всегда. В общинном натуральном хозяйстве товарно-денежное бытие общинника отсутствовало. И поэтому там не было ни рабочего, ни свободного времени. В натуральном хозяйстве люди работали на нужды общины и без расчёта на вознаграждение. Всё их время было необходимым для общины и не делилось на рабочее и свободное. Эти понятия зарождаются только с появлением первых форм товарного обращения и закрепляются в процессе развития товарного производства. Отсюда вывод: историчность рабочего и свободного времени следует связывать с динамикой развития товарного бытия в сменяющихся цивилизационных общественно экономических формациях.

В среде как отечественных, так зарубежных исследователей товарного производства нет единства взглядов. Одни, и их число подавляющее, исходят из того, что рынок - это явление общеэкономическое, неизменное, вечное, а изменяются лишь его внешние атрибуты. Вслед за А. Смитом, который рассматривал зарождение капиталистических отношений только на мануфактурной стадии производства, представители этого подхода настойчиво повторяют, что товарное производство явление вечно существующее, а «невидимая рука рынка» всегда будет господствовать в экономике.

Другим предпочтительна идея развития внутреннего содержания явления товарное производство. Одним из первых на этом настаивал Н. В. Хессин [6]. Есть подтверждение этой позиции в работах Элвина Тоффлера, который вводит в оборот достаточно выразительную аналогию развития мировых социальных процессов в виде океанской волны [7]. Этот подход напоминает известный анализ переходных форм в экономике, по поводу которых велась активная дискуссия в отечественной 
литературе в 20-е годы прошлого столетия. В 70-е годы, когда начинают формироваться черты постиндустриальной экономики, выходят работы Дж. Гелбрейта. [8], Д. Белла [9] и других авторов. В них даётся анализ изменений, происходящих в экономике и социальной сфере под влиянием научно-технического прогресса, и отмечается, что сквозь содержание многих атрибутов товарного производства «прорастают» элементы нового содержания.

Согласно мнению этих учёных, рыночные отношения есть всего лишь определённый ракурс рассмотрения товарного производства. Для этой группы исследователей товарное хозяйствование носит преходящий характер. Им ясно, что товарное производство представляет собой эволюционирующее явление. Вначале оно зарождается (товарный обмен, товарно-денежное обращение), затем достигает апогея своего развития (мелкотоварное или простое товарное производство), принимает капиталистическую форму (при появлении наёмного труда) и перезревает. На этой стадии оно и начинает уступать место более развитой (пост товарной) форме организации производства, подобно тому, как натуральное хозяйство постепенно вытеснялось и вытесняется по сей день товарным производством или, как отмечал Даниель Белл, аграрное производство вытесняется индустриальньлм [9].

У исследователей, признающих преходящзий характер товарного хозяйствования [10], не вызывает сомнения положение о том, что атрибуты товарного производства (товар, стоимость, деньги и т.п.) зарождаются в определённый период его развития, и при известных обстоятельствах само товарное производство обязательно начнёт уступать место более развитой форме организации. Это можно проиллюстрировать следующим образом, как представлено на рис. 1.

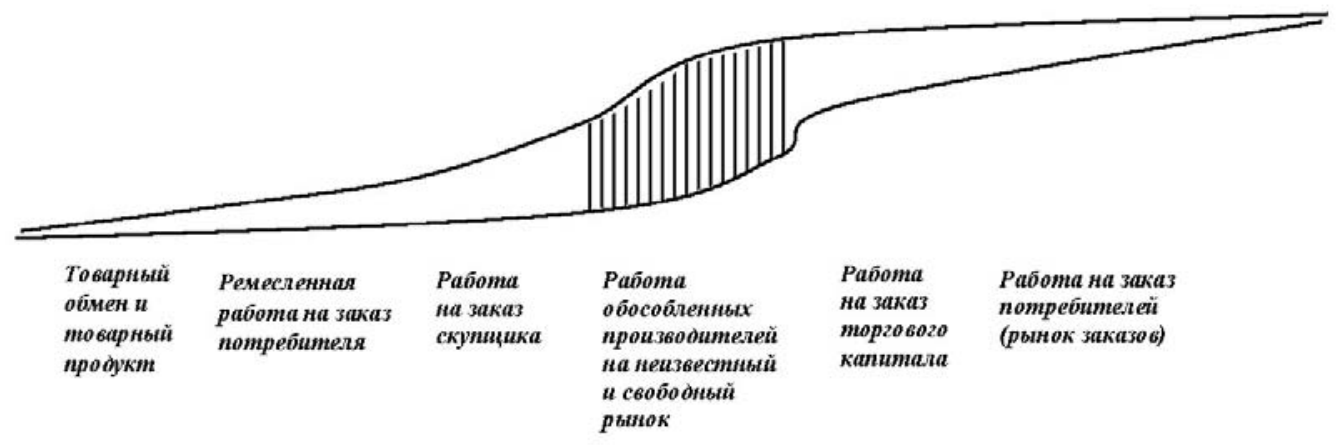

Puc. 1. Динамика развития товарной организации хозяйства

Точно так же понятия рабочее и свободное время имеют разное содержание на ранних этапах товарного обращения, в рамках классического капиталистического производства, и тем более в условиях постиндустриальной экономики. 
По мере становления и развития простейшего товарного отношения (товарного обращения) мир товаров распадается на две подсистемы: мир собственно товаров и мир денег. Появление и упрочение денежного обращения является важнейшим этапом в развитии товарной организации хозяйства.

По мере превращения рабочей силы в товар товарное производство переходит на следующую ступень своего развития, которая сменяется монополистическими формами хозяйствования, где господствует рынок заказов.

Традиционные фабрики и офисы Второй волны промышленной революции в индустриальную эпоху «с тысячами людей под одной крышей, будут очень редкими в высокотехнологичных странах будущего» [7]. «Когда начнётся игра по правилам Третьей волны, структура корпораций, как и большинства других организаций, значительно изменится. ... Вместо принципа «чем больше, тем лучше» в обществе Третьей волны возобладает принцип «адекватных масштабов» [7], характерных постиндустриальной или информационной экономике.

По-иному Элвин Тоффлер подходит и к двойственности рынков. «Экономика состоит не только из рабочих мест или оплачиваемой работы. Ранее я предложил рассматривать экономику как состоящую из двух секторов, в одном мы производим товары для обмена, в другом мы делаем вещи для себя. Один - это рыночный, или производственный сектор, другой - сектор производителя-потребителя. ... В период Второй волны широкое распространение получает рыночный. ... Продвижение Третьей волны, однако, сопровождается, как мы видели, феноменальным ростом деятельности по принципу «помоги себе сам» и «сделай сам» или «производством для себя». Выходя за рамки обычного хобби, такое производство приобретает всё большее экономическое значение. ... По мере того, как Третья волна приводит производство для обмена и «производство для себя» в большее равновесие, возрастают требования «сбалансированного» образа жизни» [7].

Итак, здесь и далее будем исходить из того, что понятия рабочее и свободное время появляются не в общинном натуральном хозяйствовании, где все затраты усилий общинников определяются необходимым временем, позволяющим выживать общине, а с возникновением первых неразвитых слабых сигналов в виде форм дарения, которые вызревают в натуральном хозяйствовании и содержат в себе зарождение революиионного момента или предвестника противоречия конкретного и абстрактного труда, свойственного товарно-денежному бытию. Иначе говоря, зарождающееся товарное бытие постепенно формирует у общинников представление о рабочем и свободном времени отдельного человека.

Поскольку общины вели хозяйствование изолированно, постольку и контакты между общинами отсутствовали. Только во время военных столкновений, сопровождающихся переселением общин, или под воздействием стихийных бедствий возникают невольные, недоброжелательные контакты с иноплеменниками. Подрыв 
изолированности общины происходит спонтанно. Миролюбивые контакты между общинами порой завершались актами дарения.

Таким образом, акты дарения неких благ одной общиной представителям другой и являются прообразом случайного товарного обмена в рамках подрывающегося натурального хозяйствования. Этот процесс можно изобразить в виде точек внутри натурального хозяйства, которые дают толчок к появлению и развитию актов товарного обмена, т.е. революционного момента в переходе к товарной организации производства.

По мере подрыва изолированности общины и увеличения числа актов дарения в недрах подрывающегося натурального хозяйствования, по имманентным ему законам, формируется неустойчивый товарный обмен (переходная форма), который впоследствии даёт толчок развитию вначале товарному обращению, а затем и системе товарно-денежных отношений. Именно такие зародыши следует искать в качестве «слабого сигнала» или некоего революичонного момента, прорастающего сквозь перезрелое товарное содержание в постиндустриальной экономике.

По мере развития товарного обращения формируются эпизодические институты мелкотоварного производства или, как сейчас принято называть, семейный бизнес. Постепенно избавляясь от феодальных форм зависимости (например, замена барщины оброком), мелкотоварное производство (семейный бизнес) начинает работать преимущественно на местный рынок. В результате формируется классический строй обособленных производителей, связанных рынком.

Так незамысловато в рамках подрывающегося натурального хозяйствования воспроизводится переходная форма натурального хозяйствования, в которой содержатся элементы нового, революичинного момента зарождающейся товарной организации производства.

Известно, что рынок рабочей силы отсутствует и в условиях товарного обращения, и при совершенной конкуренции, и при простом товарном производстве. Но когда рабочая сила становится товаром, товарное производство выходит на наивысшую стадию своего развития. Именно в этот момент зарождается капитал и формируется рынок рабочей силы. Именно в этих условиях формируется подчинение труда капиталом и, по словам Е. Прескотт и М. Висшер, упрочивается организационный капитал [13], когда наёмные работники добровольно признают за менеджером права на получение согласия работников в определённой мере подчиняться координатору производства. Здесь речь идёт об экономическом подчинении труда капиталом. Но мы знаем эпохи и внеэкономического подчинения труда (рабская или феодальная организация).

Рабочая сила расходуется во времени и под контролем координатора производства. Измеритель - использованное рабочее время. Следует обратить внимание на то, что рабочее время может рассматриваться как физическое, или 
неисторическое явление, а может быть связанным с определённой формой организации производства, т.е. с неким исторически конкретным феноменом. Физическим временем измеряются затраты конкретного труда. Например, физическим временем может измеряться продолжительность рабочего дня. В цене товара «сидит» исторически конкретное рабочее время в виде стоимости или времени осуществления общественно необходимых затрат труда. Достаточно вспомнить хрестоматийный пример из опыта Э. Мэйо (позже названного эффектом Хоторна), проведённого на одной из фабрик в начале 20-х гг. прошлого столетия. Для работников вводились четыре перерыва по 10 минут и выяснилось, что производительность труда повышалась, несмотря на формальные потери 40 минут [14]. По мере развития капитала расширяется и интернационализируется рынок труда. Набирает влияние исторически конкретное рабочее время.

Исторически конкретным рабочее время ощущается через стоимость продукта, в основе которой лежит абстрактный труд. Эволюция товарного производства сопровождается развитием содержания абстрактного труда с учётом смены технологических укладов.

Замещение человеческого труда машинами на новом технологическом уровне товарного производства К. Маркс заметил ещё в «Экономических рукописях 18571859 годов». «Труд перестал охватывать процесс производства в качестве господствующего над ним единого начала [15, с. 204]. На смену живому труду приходит овеществлённый труд, осуществляемый системами машин, которые организованы как абстрактная, неживая рабочая сила с помощью науки (или знаний) [15, с. 205]. «Сбережение рабочего времени равносильно увеличению свободного времени, т. е. времени для того полного развития индивида, которое само, в свою очередь, как величайшая производительная сила обратно воздействует на производительную силу труда». [15, с. 206]. Это самая общая характеристика исторически конкретного анализа природы свободного времени при условии, что в общественном хозяйствовании нет переходных моментов товарной организации производства. В этой трактовке именно свободное время является истинной формой измерения богатства общества будущего, вырастающего из информационной или постиндустриальной организации общественного производства пространством для свободной творческой деятельности человека без обязательств и принуждения. Именно об этом пытались писать исследователи, анализирующие процессы превращения науки в непосредственную производительную силу в виде креативной деятельности свободных от принуждения людей к тому же без расчёта на вознаграждение.

Некие видимые на сегодня черты исторически конкретного свободного времени, при условии наличия моментов умирающего господства товарной организации производства, не могут не сохранять в себе «родимых пятен» последнего. Отсюда 
появляются предположения о наличии рынка свободного времени [16] в информационной организации производства, о досуге как форме использования свободного времени, о капитализации свободного времени. И Д. Белл, и К. Маркс обращают внимание на то, что мерилом в современной экономике всё более становится не столько рабочее время, сколько свободное время индивида и общества. В постиндустриальном обществе наблюдается переход от принудительного учёта рабочего времени работника к креативной свободе, основанной на использовании свободно времени индивида и общества. На наших глазах намечается процесс смены форм учёта затрат человеческого труда через рабочее время, на использование свободного времени в качестве оценочного измерителя.

Представляется, что подрыв товарного производства и формирование постиндустриальной или информационной экономики (экономики знаний) влечёт констатацию гибели индустриальной эпохи. Наметился переход к оценкам свободнылм временем креативного, добровольного труда людей, труда без принуждения и без расчёта на вознаграждение. В период господства информационной экономики происходит процесс раздвоения рынка труда и трансформации реальной стоимости наёмной рабочей силы. Положено начало возникновению форм, в которых мерой креативного труда работников становится свободное время.

Свободное время, так же как и рабочее, в товарной организации производства бывает физическим или неисторическим явлением. Свободное время как неисторическое явление может характеризоваться как нерабочее время, или время, отличное от рабочего. Но одновременно в постиндустриальную эпоху свободное время всё больше используется для творчества, для развития индивидов. В период досуга деятельность человека осуществляется с целью получения удовлетворения, носит характер деятельности, которая развивает набор потребительских предпочтений и формирует новый спектр навыков, способных развивать человека как личность. При этом такая деятельность осуществляется не под давлением извне (без страха перед грядущим наказанием или без ожидания голодной перспективы), не исходя из расчёта на вознаграждение, а добровольно и без принуждения. Побудительным мотивом такой деятельности является самоудовлетворение от творчества за пределами матрицы, обязывающей подчиняться властным отношениям организатора трудовой деятельности. На это обращают внимание и Э. Тофлер, и Д. Белл, и К. Маркс, и Н. Хессин.

Форм креативной деятельности граждан, в которые включены некие революционные моменты, содержащие элементы исторического понимания свободного времени, и которые прорастают сквозь товарное содержание постиндустриальной экономики, немного. Но кое-что можно рассматривать в качестве прообраза или слабого сигнала формирующейся и в перспективе грядущей организации общественного бытия. 
Например, информационная или постиндустриальная экономика изобилует созданием всевозможных социальных сетей, которые стали неотъемлемой частью жизни общества. Многие считают, что значительная часть общения переместилась в интернет-пространство. Социальная сеть - это IT-платформа, которая обеспечивает поддержание связи между людьми, даже когда они находятся далеко друг от друга. Участники сети, с одной стороны, осуществляют свою деятельность добровольно, во внерабочее время и в силу своего таланта. В этой части - это зародыш революционного момента нового, не товарно-денежного бытия человека. Но, с другой стороны, некоторые блогеры зарабатывают немалые средства на рекламе. И стремление к вознаграждению уродует «свободное время» как революционный зародыш новой формы организации хозяйствования. Количество «лайков» блогер может ощущать через доходы от размещаемой рекламы, а с другой стороны, их число может показывать, насколько сэкономлено время участников сети от использования предложения одного из её членов.

Во втором случае мы имеем дело с формированием революционного момента в понятии «свободное время», который прорастает сквозь товарное содержание в постиндустриальной экономике. Предположим, количество временных лайков позволит гражданину обеспечить беспрепятственный или более льготный доступ к ограниченным ресурсам сообщества для проверки и реализации его креативных устремлений. Для этого должны получить широкое развитие технопарки, дома творчества, которые могут рассматриваться в качестве условия для креативной деятельности изобретателей. Кроме того, индивидуальные или коллективные формы проведения досуга (библиотеки, собирательство антиквариата, музеи, гражданские институты, например, общество филателистов, общества охоты и рыболовства и т.д.) должны получить новое звучание и стать востребованными для креативной деятельности. Именно здесь должен быть обеспечен приоритетный доступ желающих в свободное время пользоваться высокотехнологичным оборудованием. И эта деятельность должна диктоваться не вынужденностью работника создавать необходимый продукт, не желанием получить вознаграждение, не стремлением избавиться от голода или увильнуть от внеэкономического принуждения. Побудительным мотивом этой деятельности является самоудовлетворение от творчества за пределами матрицы, обязывающей подчиняться властным отношениям организатора трудовой деятельности, стремление развить свой творческий потенциал, расширить спектр притязаний, которые дадут большее самоудовлетворение в творчестве. Эта деятельность и будет измеряться свободным временем.

Любопытной формой, воспроизводящей элементы нового качества содержания свободного времени, является волонтёрство. Добровольцы, или волонтёры, осуществляют добровольно, без принуждения безвозмездную деятельность на благо общества и отдельных граждан. Французское слово volontaire («волонтёр») 
произошло от латинского voluntarius («добровольный»). Так что галлицизм «волонтёр» - это полный синоним русского «доброволец». Это зафиксировано в пятой статье Ф3 № 135 «О благотворительной деятельности и добровольчестве (волонтёрстве)», одобренного Советом Федерации 31 января 2018 г.

Деятельность добровольцев очень близка к новой исторической сущности категории «свободное время». Вместе с тем, волонтёры нуждаются в обеспечении корпоративной одеждой (жилетки, футболки, кепки, рюкзаки с логотипом мероприятия или добровольческого движения), печатными материалами. В такой форме поддержка волонтёрского движения применялась в 2018 г. в Республиках Алтай, Тыва, Камчатском крае, Астраханской области и др. Иногда волонтёрам вручают «Личные книжки волонтёра», фиксирующие их достижения, полученный опыт и время, затраченное в рамках добровольческой (волонтёрской) деятельности, эта информация может быть использована в качестве бонуса при поступлении в высшие учебные заведения. Личные книжки добровольцев в 2018 г. вручались в Республиках Коми, Марий-Эл, Удмуртской Республике, Красноярском крае, Астраханской, Тюменской областях, г. Севастополе и др. [11].

Таким образом, современные волонтёрские усилия в условиях господства товарно-денежного бытия предполагают некую организационную структуру, координирующую их деятельность, ожидания поощрения при поступлении в высшие учебные заведения, желания получить «Личную книжку волонтёра», где фиксируются его достижения, полученный опыт и время, затраченное в рамках добровольческой (волонтёрской) деятельности. Это и есть родимые пятна товарноденежного бытия. Креативная деятельность свободных индивидов грядущей общественной организации предполагает действия гражданина без любой формы принуждения и по велению собственного желания.

Интересной формой, воспроизводящей элементы нового качества содержания свободного времени, является безусловный основной доход (БОД), в его трактовке как способа воздействия на социальное и физиологическое благополучие населения через достойное питание, свободное время и так далее» [12, с. 53]. Нам представляется, что в такой зародышевой форме как безусловный основной доход (БОД) усматривается способ увеличения свободы членов общества, предоставляющий возможность посвящать себя творческой деятельности, которая оценивается не рабочим временем общества, а с помощью оценки свободным временем затрат их творческих усилий. Дисциплина принуждения к трудовой деятельности с помощью БОД постепенно устраняется, уходит в прошлое, и матрица управления несвободного труда ослабевает.

Представляется, что у этого инструмента (БОД) нет потенциала преодоления бедности. С его помощью бедность не изжить по многим причинам, в том числе и потому, что бедность - явление историческое, присущее товарной организации 
производства, и потому, что бедность - явление относительное. В рамках товарной организации производства бедность непреодолима. Её можно лишь кое-как и коегде сгладить.

Безусловный основной доход (БОД) также не способен обеспечить полной занятости, пока не рухнет рынок труда. А последний предполагает наличие резервной армии труда.

В явлении безусловного основного дохода (БОД) нет также потенциала обеспечения доступности сощчиальной защитыь. При применении такого инструмента имеет место видимость повышения социальной защиты граждан, поскольку люди получают средства, и в каждом конкретном случае им оказывается социальная поддержка. Однако собственно формой социальной защиты БОД можно считать только в обществе, базирующемся на товарной организации производства, при условии использования наёмного труда, черпаемого с рынка труда. Осуществляемая деятельность в этих условиях измеряется рабочим временем работников. Нам же представляется, что в этой форме (БОД) усматривается проявление способа увеличения свободы членов общества и предоставляется возможность посвящать себя творческой деятельности, которая оценивается не рабочим временем общества, а с помощью оценки свободным временем затрат творческих усилий.

При наличии развитой системы, базирующейся на принципах БОД, в прошлое будет мучительно уходить понятие рабочего времени и проявится революционный момент свободного времени в деятельности свободных индивидов грядущей общественной организации.

Формирование постиндустриальной или информационной экономики влечёт гибель индустриальной эпохи, а вместе с тем и угасание роли рабочего времени. На базе зарождающихся форм волонтёрской деятельности, функционирования couиальных сетей, обеспечения свободного доступа желающих в свободное время пользоваться высокотехнологическим оборудованием, инструментами доступа к культурным ценностям, формирования безусловного основного дохода, проведения конкурсов и выделения грантов, вручения ежегодных премий за интеллектуальные результаты, награждения за многолетнюю творческую деятельность, стимулирования движения рационализаторов и изобретателей, с помощью руководства кружками творчества, проведения мастер классов и т.п. будет обеспечиваться переход к оценке креативной деятельности человека свободным временем. Анализ перспективности перечисленных форм только обогатится, если по ним будут периодически проводиться Форсайт проекты [10], в ходе реализации которых всё конкретнее смогут проявиться революционные черты нового понимания свободного времени. 


\section{Список литературы}

1. Мор, Т. Утопия / Т. Мор. - Москва : Изд-во Академии наук СССР, 1953. $302 \mathrm{c}$.

2. Свободное время // Библиотекарь.Ру. - URL: http://www.bibliotekar.ru/encSemya/145.htm (дата обращения: 03.05.2021).

3. Свободное время как экономический ресурс. - URL: https://ozlib.com/8078 02/zhurnalistika/svobodnoe_vremya_ekonomicheskiy_resurs (дата обращения: 03.05.2021).

4. Свободное время. - URL. https://science.wikia.Org/ru/wiki/\%D0\%A1\%D0\% B2\%D0\%BE\%D0\%B1\%D0\%BE\%D0\%B4\%D0\%BD\%D0\%BE\%D0\%B5_\%D0\%B2\% D $1 \% 80 \% \mathrm{D} 0 \% \mathrm{~B} 5 \% \mathrm{D} 0 \% \mathrm{BC} \% \mathrm{D} 1 \% 8 \mathrm{~F}$ ?action=edit\&section=8\#cite_note-glossary.ru-0 (дата обращения: 03.05.2021).

5. Ельмеев, В. Я. Социальная экономия труда: общие основы политической экономии / В. Я. Ельмеев. - Санкт-Петербург : Изд-во С.-Петерб. ун-та, 2007. - 576 с.

6. Хессин, Н. В. В. И. Ленин о сущности и основных признаках товарного производства / Н. В. Хессин. - Москва : МГУ, 1968. - 166 с.

7. Тоффлер, Э. Третья волна / Э. Тоффлер. - Москва : АСТ, 2010. - 784 с.

8. Гэлбрейт, Дж. К. Экономические теории и цели общества Дж. К. Гэлбрейт. - Москва : Прогресс, 1976. - 408 с.

9. Bell, D. The coming of post-industrial society: A venture of social forecasting / D. Bell. - New York : Basic Books, 1973. - 616 p.

10. Третьяк, В. П. Форсайт подрыва товарного производства / В. П. Третьяк. Москва : Русайнс, 2021. - 188 с.

11. Мониторинг реализации мер поддержки добровольчества (волонтерства) в субъектах Российской Федерации : доклад. - URL: https://ac.gov.ru/archive/files/publi cation/a/21345.pdf (дата обращения: 16.08.2021).

12. Трубин, В. // Базовый доход: пролог к социальной политике XXI века? : международная научно-практическая конференция. [14 11 2018] : [стенограмма Пленарной сессии «Базовый доход: постановка проблемы»]. - Москва : ВШЭ, 2018. - C. 35-38. - URL: https://isp.hse.ru/data/2019/01/09/1143757431/Конференци я\%20БД_14-11-2018_стенограмма.pdf (дата обращения: 17.08.2021).

13. Prescott, E. Organization capital / E. Prescott, M. Vissher // Journal of Political Economy. - 1980. - № 88. - P. 446-461.

14. Рабочее и свободное время как категории экономической теории. - URL: http://moyuniver.net/rabochee-i-svobodnoe-vremya-kak-kategorii-ekonomicheskoj-teorii/ (дата обращения: 03.05.2021).

15. Маркс, К. Собрание сочинений / К. Маркс, Ф. Энгельс. - Москва : Политиздат, 1969. - Т. 46, ч. 2. -618 с.

16. Балацкий, Е. Свободное время как фактор экономического равновесия // Вестник Российской Академии наук. - 1999. - Т. 69, № 11. - С. 1018-1025. 
17. Пруденский, Г. А. Проблемы рабочего и внерабочего времени / Г. А. Пруденский. - Москва : Наука, 1972. - 335 с.

\section{References}

1. Mor T. [Utopia]. Moscow: Publishing house of the USSR Academy of Sciences, 1953. $302 \mathrm{p}$.

2. Free time. Librarian.Ru. Available at: http:/www.bibliotekar.ru/enc-Semya/145.htm (acessed 05 March 2021). (In Russian).

3. Free time as an economic resource. Available at: https://ozlib.com/807802/zhu rnalistika/svobodnoe_vremya_ekonomicheskiy_resurs (accessed 05 March 2021). (In Russian).

4. Free time. Available at: https://science.wikia.Org/ru/wiki/\%D0\%A1\%D0\%B2 $\% \mathrm{D} 0 \% \mathrm{BE} \% \mathrm{D} 0 \% \mathrm{~B} 1 \% \mathrm{D} 0 \% \mathrm{BE} \% \mathrm{D} 0 \% \mathrm{~B} 4 \% \mathrm{D} 0 \% \mathrm{BD} \% \mathrm{D} 0 \% \mathrm{BE} \% \mathrm{D} 0 \% \mathrm{~B} 5 \_\% \mathrm{D} 0 \% \mathrm{~B} 2 \% \mathrm{D} 1$ $\% 80 \% \mathrm{D} 0 \% \mathrm{~B} 5 \% \mathrm{D} 0 \% \mathrm{BC} \% \mathrm{D} 1 \% 8 \mathrm{~F}$ ?action=edit\&section=8\#cite_note-glossary.ru-0 (accessed 05 March 2021). (In Russian).

5. Elmeev V. Ya. Sotsial'naya ekonomiya truda: obshchie osnovy politicheskoi ekonomii [Social economy of labor: general foundations of political economy]. St. Petersburg: Publishing house of St. Petersburg. Univ., 2007. 576 p.

6. Hessin N. V. V. I. Lenin o sushchnosti i osnovnykh priznakakh tovarnogo proizvodstva [V. I. Lenin on the essence and main features of commodity production]. Moscow: Moscow State Univ. Publ., 1968. 166 p.

7. Toffler E. Tret'ya volna [The Third Wave]. Moscow: AST Publ., 2010. 784 p.

8. Galbraith J. K. Ekonomicheskie teorii $i$ tseli obshchestva [Economic theories and goals of society]. Moscow: Progress Publ., 1976. 408 p.

9. Bell D. The coming of post-industrial society: A venture of social forecasting. New York: Basic Books, 1973. 616 p.

10. Tretyak V. P. Forsait podryva tovarnogo proizvodstva [Foresight undermining commodity production]. Moscow: Rusains Publ., 2021. 188 p.

11. Monitoring the implementation of measures to support volunteering in the constituent entities of the Russian Federation: report. Available at: https://ac.gov.ru/a rchive/files/publication/a/21345.pdf (accessed 16 August 2021). (In Russian).

12. Trubin V. In: Basic income: a prologue to social policy of the XXI century?: international scientific and practical conference. 2018, November 14. Transcript of the Plenary Basic Income: Problem Statement. Moscow: Higher School of Economics, 2018, pp. 35-38. Available at: https://isp.hse.ru/data/2019/01/09/1143757431/Confer ence\%20BD_14-11-2018_stenogram.pdf (accessed 17 August 2021). (In Russian).

13. Prescott E., Vissher M. Organization capital. Journal of Political Economy, 1980, no. 88, pp. 446-461. 
14. Work and free time as a category of economic theory. Available at: http://moyuniver.net/rabochee-i-svobodnoe-vremya-kak-kategorii-ekonomicheskoj-teorii/ (accessed 05 March 2021). (In Russian).

15. Marx K., Engels F. Sobranie sochineniü [Collected works]. Moscow: Politizdat Publ., 1969. Vol. 46, part 2. 618 p.

16. Balatsky E. Svobodnoe vremya kak faktor ekonomicheskogo ravnovesiya [Free time as a factor of economic equilibrium. Vestnik Rossiiskoi Akademii nauk, 1999, vol. 69, no. 11, pp. 1018-1025.

17. Prudensky G. A. Problemy rabochego i vnerabochego vremeni [Problems of working and non-working time]. Moscow: Nauka Publ., 1972. 335 p. 